\title{
CIDADE, ATORES E PROCESSOS SOCIAIS: O LEGADO SOCIOLÓGICO DE LÚCIO KOWARICK
}

\author{
Lúcio Kowarick. Escritos urbanos. São Paulo, Editora 34, 2009 \\ e Viver em risco. São Paulo, Editora 34, 2009.
}

\section{Irlys Alencar Firmo Barreira}

No campo das ciências sociais desenvolvidas no Brasil a sociologia urbana constitui um dos ramos importantes do saber, caracterizado por recortes significativos que se voltam para entender as cidades em processos variados de transformação. Uma espécie de conhecimento acumulado, com influências teóricas nacionais e internacionais, buscou problematizar as metrópoles em sua face plural e dinâmica, conferindo destaque aos últimos trinta anos do século passado.

De fato, a sociologia urbana que nas décadas de 1960 e 1970 convivia com os estudos voltados para a questão agrária adquiri, no decênio seguinte, hegemonia sobre outros recortes analíticos, conferindo às cidades um estatuto paradigmático da sociedade brasileira.

Reflexôes sobre desigualdades econômicas, políticas públicas, conflitos, movimentos, violência, direitos e cidadania, entre outras, desembocam em espaços urbanos, apontados como verdadeiro palco de fatos sociais indutores de problemáticas sociológicas contemporâneas. A “questão urbana”, título de um dos livros de Manuel Castells (1983) permeia o escopo de investigações sobre cidades, influenciando pesquisas antenadas com as transformaçōes da realidade urbano-industrial do Brasil e da América Latina.

O olhar crítico de Lúcio Kowarick sobre a dinâmica citadina é tributário desse contexto, firmando-se no cenário intelectual como pesquisa de longa duração, singularizada pela visita recorrente e criativa aos mesmos objetos. A pobreza e a expansão urbana em sua feição social e política constituem um fio analítico por meio do qual o autor interpreta características peculiares à cidade de São Paulo, potencialmente extensivas à realidade de outras metrópoles. Trabalhadores, moradores e desempregados são personagens inseridos no universo da segregação social, oscilando entre a tragédia cotidiana e a estratégia dos espaços de luta pelo reconhecimento dos direitos de cidadania. 
A compreensão da vida urbana como expressão múltipla de processos macroestruturais serve de esteio às reflexões analíticas de Lúcio Kowarick, sendo espécie de tela ampla na qual se desenrolam os dramas das classes menos favorecidas. São dramas configurados, principalmente, na equação trabalho versus moradia, estando associados às formas de reprodução da vida social de setores populares, incluídos e excluídos do mundo do trabalho, nas condições singulares de um país marcadamente desigual, no qual se afiguram os dilemas da associação entre pobreza e expansão urbana.

Com base em pesquisa etnográfica realizada em São Paulo e informaçōes secundárias, provenientes de outros contextos, Lúcio Kowarick une em sua produção bibliográfica dados empíricos com reflexôes teóricas de grande porte. São textos que vêm, ao longo do tempo, influenciando uma geração de pesquisadores interessada principalmente em dois temas: o crescimento das metrópoles com efeitos sobre os mecanismos de segregação social e política e o registro analítico das formas coletivas de organização pela conquista da moradia e outros bens de consumo coletivo.

Com a reedição do livro Escritos urbanos ([2001], 2009), composto de textos revisitados e ampliados e o lançamento recente da obra Viver em risco (2009), observa-se um legado importante na produção sociológica que merece ser apreciado sob o prisma do seu poder de impacto na formulação de um olhar crítico sobre as cidades contemporâneas.

É este o objetivo deste texto. Busco examinar e contextualizar o contributo das reflexões de Lúcio Kowarick sobre o desenvolvimento da sociologia urbana brasileira, acentuando a formulação e a atualização de perspectivas teóricas, observando ainda, de forma rápida, eventuais potencialidades de aplicação de sua análise a outros contextos citadinos.

Inicialmente é importante pontuar o campo de reflexão sociológica no qual o autor se insere. Seu porto de partida ancora-se em uma abordagem teórica marxista, embora a ela não se restrinja, que se renovou na tentativa de pensar a atuação social de segmentos populares para além das práticas concernentes ao mundo do trabalho. Emergiu, dessa perspectiva analítica, a capacidade de leitura dos mecanismos de reprodução da vida social no espa- ço citadino, mantendo o foco dos conflitos em sua expressão mais abrangente, não restrito ao "coração da fábrica”, mas ampliado, e algumas vezes articulado, ao chão da experiência de moradia.

Outro mecanismo de renovação do marxismo, também incorporado pelo autor e tributário de analistas como Francisco de Oliveira, refere-se à capacidade de observar a expansão capitalista brasileira em convivência desigual e combinada com o alargamento da pobreza. Desenvolvimento, riqueza e miséria constituem tramas de uma mesma história, em contraponto seqüencial à teoria da marginalidade e às concepções dualistas que caracterizaram parte significativa da produção do pensamento brasileiro e latino-americano, desde o final da década de 1960.

As cidades são, na abordagem de Kowarick, permeadas por uma condição de desigualdade refletida nos temas da ausência ou da precariedade da moradia e da oferta limitada e estratificada de equipamentos e serviços públicos. Uma visão de totalidade implicou, portanto, na percepção da vida urbana em sua dinâmica contraditória, destacando-se a presença de processos sociais de acumulação e segregação verificados nas metrópoles como lugar por excelência de validação e expansão do capital imobiliário. O surgimento de periferias, também induzido pelo disciplinamento do poder público, seria a expressão mais nítida da estratificação espacial de classe, observada principalmente na cidade de São Paulo.

\section{Espoliação urbana: uma chave de leitura}

As cidades brasileiras, como palco de desigualdades sociais e conflitos, foram interpretadas com base no conceito de espoliação urbana, traduzindo os supostos da desigualdade em uma sociedade cujo desenvolvimento era acompanhado de formas variadas de "exclusão social". A espoliação urbana indicava a existência de privaçôes ou carências que pareciam dispersas ou casuais: traduzia a continuidade das formas de extorsão instituídas no âmbito do trabalho, abarcando espaços outros de moradia, transporte e demais situaçôes necessárias à sobrevivência dos indivíduos nas grandes metrópoles.

O conceito de espoliação, sistematizado mais especificamente em obra anterior (Kowarick, 
1983), teve por objetivo agregar, de modo estrutural, a idéia de uma força de trabalho submetida a formas de extorsão que extrapolavam o domínio da fábrica. $\mathrm{O}$ uso deficitário do transporte, a precariedade da moradia, a dificuldade de acesso a bens coletivos de consumo configuravam a vigência de condições insatisfatórias de reprodução social, típicas do capitalismo consolidado em uma metrópole brasileira de "subdesenvolvimento industrializado".

Mais do que denunciar as condiçôes de vida na cidade, o conceito de espoliação urbana é uma "arma teórica" capaz de atingir o cerne das desigualdades sociais, definindo-se não só pela carência de bens de consumo coletivo tais como moradia, transporte, água e luz, estendendo-se também a práticas de autoconstrução e conseqüente aumento da jornada de trabalho. A espoliação urbana constituía uma espécie de "mais valia" peculiar a indivíduos destituídos de direitos de acesso a bens coletivos e garantias cotidianas de sobrevivência.

O conceito permitiu ainda inverter a lógica da culpabilidade da questão social atribuída a indivíduos, presente na idéía de que a cidade seria concebida como tela em aberto a partir da qual todos poderiam tecer a sua história livremente. A espoliação urbana revelava, portanto, a matriz da desigualdade espalhada nas práticas rotineiras do ir e vir ao trabalho, no despertar precoce para evitar o enfrentamento de filas, enfim, em todos os sentidos de alerta e fadiga não computados no "tempo que conta" - o do emprego formal remunerado. A espoliação urbana passa também atualmente a explicitar-se no medo, na compreensão das adversidades e no senso de realidade dos obstáculos a transpor para cumprir as tarefas rotineiras.

O conceito de espoliação urbana permitiu, enfim, perceber o descortinar da vida citadina em sua expressão difusa e descontínua, funcionando como chave de leitura e interpretação capaz de unir processos sociais e vivências cotidianas. Trata-se de um suporte analítico que influenciou muitos trabalhos de pesquisa, criando uma idéia integradora de cidade baseada nas dinâmicas de exploração e reprodução das desigualdades sociais.

O papel conferido pelo autor ao exame de processos macro-estruturais não se descuidou, por outro lado, do olhar voltado para a força emergente de movimentos sociais, presentes desde o final da década de 1970. Dando seqüência ao tema da espoliação, uma das reflexōes postas por Lúcio Kowarick, muitas vezes acentuada em seus cursos de sociologia urbana ministrados na USP, era a passagem das carências para as mobilizaçōes sociais, isto é, a transformação da condição de espoliado em ator social e político, organizado em torno de movimentos.

\section{Das carências às mobilizaçóes}

A obra de Lúcio Kowarick dialoga fortemente com o cenário citadino insurgente que emerge nas décadas de 1970 e 1980. Destaca-se, nesse período, o crescimento forte e irradiador de organizaçóes de bairros populares baseadas em demandas por habitação, saúde, educação e moradia. Assiste-se em todo o país, movido pelos ventos da abertura democrática, ao pipocar de associação de moradores com práticas contestatórias de acampamento em locais públicos e passeatas visando à conquista de "direitos urbanos". As mobilizaçôes de maior poder de impacto, nomeadas de "ação direta", instituíram a denúncia nas ruas que caracterizou as estratégias mais insurgentes na esfera pública. ${ }^{1}$

Alguns elementos conjunturais merecem ser mencionados. Os distintos movimentos, não obstante a diversidade que os caracterizava, tiveram apoio direto ou indireto de partidos de esquerda e setores progressistas da Igreja católica, unificandose em um campo simbólico mais vasto de "luta por democracia e direitos sociais".

A passagem das carências às mobilizações não poderia ser mecânica na percepção de Lúcio Kowarick, devendo ser entendida com base em processos vivenciados no contexto específico de múltiplas experiências. Estas se reportavam ao viver cotidiano dos moradores em seus enfrentamentos freqüentes, tendo em vista a necessidade de superar os reveses da vida na metrópole. O conflito era então pensado como estando organizado a partir de demandas coordenadas e dotadas de visibilidade. A crítica sobre a naturalidade da associação entre carências e conflitos chamava atenção para o aprofundamento analítico dessa mediação, geralmente formalizada 
por movimentos sociais no uso da linguagem dos direitos. Os conflitos eram, portanto, permeados por discursos e percepções simbólicas que incidiam sobre posições sociais em confronto.

O caráter não determinista dos movimentos, fundamentado na noção de experiência, bebeu nas fontes de renovação do marxismo por meio de Thompson (1979), para quem o fazer-se da classe social não supunha um destino político, mas a construção permanente da luta tecida no chão da história. Enfocando a prática de atores sociais, designados como "sujeitos coletivos", o conceito de experiência em Thompson constituiu uma espécie de alavanca teórica importante. Foi utilizado para recompor trajetórias de segmentos sociais que não se definiam somente por posições objetivas, ocupadas na estrutura produtiva, mas com base em uma identidade de interesses historicamente construída. Em substituição a uma definição prévia do sentido a ser conferido às lutas sociais, presente em postulações marxistas mais convencionais, Thompson priorizou a análise sobre as classes trabalhadoras a partir de seu agir cotidiano: a ideologia gestada no plano concreto dos acontecimentos.

A noção de experiência, que serviu de crítica ao conceito de "consciência de classe", foi apropriada no Brasil por vários estudiosos da sociologia urbana, incluindo Lúcio Kowarick, dando suporte ao exame do acúmulo de práticas sociais e políticas provenientes de vários segmentos sociais. Analisar a forma de organização e mobilização de moradores, profissionais de categorias diversas e segmentos sociais, aglutinados em torno de identidades de gênero, etnia, moradia e condições de trabalho significou, em acréscimo, conhecer a linguagem interna de atores coletivos, permeada por uma cultura de contestação, construída a partir de uma historicidade.

As incursões teóricas de Lúcio Kowarick permitiram uma análise acerca da construção da passagem das contradições urbanas aos conflitos, assim como a transformação destes em coletivos designados de movimentos sociais. Movimentos não restritos à moradia, articulando-se também a demandas salariais. O bairro e a fábrica emergiam, assim, como espaços com potencialidades de comunicação, sendo a moradia um lugar também portador de virtualidades para "pensar sobre o trabalho".
Em sugestivo artigo intitulado "Os caminhos do encontro", Kowarick (1984) em diálogo permanente com as idéias de Vera Telles (1982) refletiu sobre as conexões estabelecidas entre lutas fabris e lutas por habitação, viabilizadas por operários paulistas, movidos pelo lema dos direitos ao trabalho e à moradia digna. Afirma ainda o autor posteriormente em seu livro, Escritos urbanos, a necessidade de desenvolver novas pesquisas sobre essa conexão, enfatizando as articulações teóricas e políticas que se estabelecem entre moradia e trabalho.

Vale a pena ainda insistir sobre o debate intelectual vigente no período. Outros supostos teóricos estiveram presentes nesse momento. As contradições entre Estado e movimentos sociais, às vezes envolvendo proprietários urbanos, expressavam-se por meio de conflitos diretos, as "invasões", afirmando diferentes coletivos em processo de mobilização. A transformação dos conflitos em movimentos supunha, por outro lado, uma apresentação dos antagonismos em uma escala mais ampla, atuando a partir de dois elementos fundamentais: a visibilidade e a legitimidade. A idéia de visibilidade implicava em pensar as demandas sociais, postas no espaço público, mediante discursos e palavras de ordem. Desse modo, ocupar gabinetes governamentais, fazer passeatas e manifestações dava um sentido de presença e pertencimento de atores sociais a um coletivo simbolicamente instituído, que foi designado de "povo em movimento". As teorizaçôes sobre a idéia de sociedade civil, inspiradas em Gramsci, são apropriadas nesse momento destacando-se, entre elas, a percepção dos espaços públicos de elaboração dos conflitos em consonância direta ou indireta com o Estado.

Buscar a legitimidade das ações de protesto exigiu dos movimentos sociais a efetivação de suportes institucionais, tendo em mira a abertura de espaços de adesão e reconhecimento. Nesse sentido, a Igreja católica progressista serviu de suporte a movimentos de resistência à expulsão de moradias construídas em terrenos ilegais, atuando também em organizaçôes populares ligadas ao consumo e à melhoria do custo de vida.

A ênfase conferida à sociedade civil, em oposição ao Estado, presente em muitos trabalhos sobre movimentos sociais, foi criticada por Ruth Cardoso (1983) em artigo que se tornou espécie de clássi- 
co nas discussões sobre a temática. Argumentava a autora que a forma como a reflexão sobre os movimentos sociais urbanos foi reconstruída enfatizava, com exagero, o lado dinâmico da sociedade civil, omitindo a presença do Estado. A valorização de práticas consideradas espontâneas, tais como a mobilização de moradores, usuários de transportes coletivos, donas de casas e diversas categorias profissionais, indicava manifestações da sociedade civil que eram percebidas como expressão de uma "natureza popular", distante das articulações políticas com o Estado. O que Ruth Cardoso afirmava era a perspectiva contraditória e complexa da relação entre movimentos urbanos e poder político, que não se movia por uma essência democrática, advinda do povo, ou autoritária, que vinha do Estado. A necessidade de incorporar às análises uma dinâmica relacional entre Estado e movimentos sociais indicaria, segundo o ponto de vista da antropóloga, a capacidade de os movimentos serem, inclusive, incentivados pelo próprio Estado.

Em uma postura analítica diferenciada, a comunicação complexa entre Estado e sociedade foi tratada por Oliveira (1994), considerando que a idéia de renovação teórica, no contexto da sociedade brasileira, supunha uma abordagem com capacidade de captar a emergência de novos atores no espaço público. Para o economista e sociólogo seria necessário, no estudo dos movimentos sociais, reverter a tradição de uma interpretação sociológica que pensava, prioritariamente, o Estado caminhando em direção à sociedade". Percebendo que as transformações econômicas e sociais, vigentes até o final do século XX, geraram deslocamentos na estrutura e na temporalidade dos atores sociais, criando um vácuo na política, Oliveira propôs uma inversão na perspectiva analítica: a "sociedade caminhando para o Estado" teria preponderância na compreensão do contexto sociopolítico brasileiro. A ausência de interlocutores e mediadores, tais como partidos políticos, em uma sociedade recémsaída do autoritarismo, tornaria os movimentos sociais espécies de atores em comunicação direta com o Estado.

No contexto dessa reflexão, Lúcio Kowarick chamava atenção para o fato de que o Estado "politizava-se”, ao tornar-se alvo de acirradas pressōes e reivindicações. E por causa desse tipo de oposição (de classes) ele se tornava o núcleo dos conflitos, exigindo uma postura de renovação dos mecanismos clássicos de percepção das lutas sociais.

Os chamados novos movimentos sociais emergiram suscitavam também um debate inicial com alguns dos supostos teóricos do marxismo. A ênfase emprestada ao múltiplo e ao diverso questionava o sentido determinista de classe e o princípio de unidade que informavam, anteriormente, o olhar sobre as práticas sindicais.

Em substituição às polaridades estruturais, suscitadas pelo sistema produtivo, emergiam as desigualdades em face dos bens de consumo coletivos. No âmbito de uma reflexão teórica de teor mais estrutural, os conflitos sociais passaram a ser vistos no espaço de moradia, transporte, ou seja, em situaçôes vivenciadas na cidade, analisadas com base no conceito de "contradiçôes urbanas" (Castells, 1980). Foi com base no pensamento desse autor que a reflexão sobre os movimentos urbanos no Brasil e na América Latina ganhou um foco relevante, criando um olhar teórico que enfatizava o papel mediador e paradoxal do Estado, oscilando entre a garantia da reprodução da força de trabalho e a proteção ampliada do capitalismo monopolista.

A diversidade de situações históricas na America Latina, segundo as pesquisas de Castells, demonstrava a existência de formas diferentes de enfrentamento ao Estado, conferindo ao movimento citadino uma nova qualidade. Este, além de expressar uma forma direta de oposição ao Estado, era amplo o suficiente para abranger camadas diversas da população. O modelo explicativo do pesquisador espanhol, que influenciou vários pesquisadores brasileiros, entre os quais Lúcio Kowarick, permitiu uma re-atualização da teoria do conflito de classes, sobretudo em situaçōes históricas em que a queda relativa dos níveis de vida atuava como elemento acionador de conflitos. A dimensão interclassista dos movimentos refletia tanto o caráter das contradiçôes urbanas, não restritas ao trabalho, como as açôes de sujeitos coletivos organizados em circunstâncias variadas.

Reflexôes sobre práticas institucionais democráticas no âmbito dos movimentos sociais encontraram também raízes fecundas no pensamento de 
Arendt (1991), que tomou como referência a sociedade grega para analisar a atividade política efetivada na ligação entre ação e discurso, fundadora das bases de sociabilidade. Essa visão alargada da política, para além da esfera institucionalizada do Estado, foi apropriada nas pesquisas sobre movimentos sociais, interessadas no papel da linguagem e da experiência na constituição de demandas coletivas. O "direito a ter direitos", expressão da autora utilizada em muitos trabalhos sobre movimentos sociais e também empregada por Kowarick nas inferências sobre as dificuldades de efetivação da cidadania, representava a possibilidade de ampliação de um espaço democrático no qual setores sociais poderiam reivindicar mecanismos de participação e reconhecimento.

A inserção das idéias de Lúcio Kowarick nesse contexto discursivo foi movida principalmente pela tentativa de associar o tema das contradições urbanas ao das lutas sociais, também verificadas em diferentes espaços, enfatizando as mediações desse campo vasto de demandas por direitos urbanos. Caracterizava-se sua reflexão sobre a temática pela permanente busca de conexão entre fatores estruturais e interlocuções políticas.

A ênfase do período sobre a abordagem dos movimentos sociais não pode, entretanto, ser considerada linear. A própria percepção do autor desfaz a idéia de uma relação direta entre a realidade de determinada sociedade e a produção do conhecimento nela vigente, postulando que são muitos os caminhos que informam as escolhas temáticas, os recortes analíticos e as indagações teóricas.

\section{Os escritos urbanos}

A temática dos movimentos sociais e suas formas de expressão na realidade brasileira encontra-se presente no livro Escritos urbanos. $\mathrm{O}$ autor revisita nessa obra textos antigos de sua autoria, elaborando comentários e acréscimos que visam à construção de atualizações. Ao "novo caráter das lutas de classes", que pontuou as reflexôes da década de 1970, são acrescidas as questôes referentes à cidadania, à violência e à participação popular no âmbito das políticas públicas. Também a noção de espoliação urbana muda de "coloração teórica", para usar a própria expressão de Lúcio Kowarick, agregando aos elementos estruturais o tema da subjetividade de protagonistas sociais. Valoriza assim "as produçôes simbólicas realizadas por autores que confeccionam discursos com sinais positivos ou negativos sobre uma situação concreta de exclusão a partir da qual estruturam as orientações de suas açôes coletivas" (p. 14).

Os textos que compõem o livro Escritos urbanos são de caráter mais teórico, apresentando um desenvolvimento detalhado dos conceitos de contradições urbanas e espoliação. Uma reflexão de caráter mais epistemológico critica as análises que reforçam a idéia de uma estrutura social sem sujeitos, ou de uma ordem portadora de indivíduos liberados de constrangimentos estruturais, que são comuns a muitos dos estudos que sucederam as interpretações sociológicas sobre os movimentos sociais.

Um novo questionamento acrescido à temática da espoliação e das contradições urbanas emerge do exame da "exclusão social", presente especificamente após a década de 1990. Suplementos à reflexão sobre o tema da espoliação podem ser encontrados na relação entre cidadania e exclusão, tratada especificamente no quinto capítulo dos Escritos urbanos, com base no relatório de pesquisa sobre "modo e condição de vida", desenvolvido com o apoio do Cedec/Dieese, mais especificamente nos capítulos a cargo de Nabil Bonduki e Vera da Silva Telles. É nele que alguns supostos teóricos a respeito do processo de inclusão-exclusão são desenvolvidos, sendo objetivado o papel da moradia como lócus de reprodução das condições naturais, de experiências e instituição de discursos.

A moradia como ambiente de sociabilidade privada é também abrigo contra tempestades econômicas, significando o projeto de muitas famílias e o sonho de construir a casa para "não viver de aluguel”. É nesse ponto que Kowarick relativiza a crítica que sempre conferiu ao processo de autoconstrução, reconhecendo o lado paradoxal dessa prática que, mesmo sendo fruto do trabalho familiar centralizado, leva ao acúmulo de bens, compensando as demais alternativas habitacionais precárias. A casa própria é, portanto, o símbolo de um "vencer na vida", isto é, a vitória de uma moralidade 
que valoriza a família unida e honesta, perfazendo a condição de "cidadão privado", em uma sociedade cuja vida pública é excludente e violenta.

No capítulo designado "Fatias da nossa história recente”, Lúcio Kowarick revisita o conhecido livro São Paulo 1975: crescimento e pobreza (1976), organizado em parceria com Vinicius Caldeira Brant, no qual reafirma a importância concedida, àquela época, ao tema da segregação, insinuandose a já embrionária presença do conceito de espoliação urbana.

Incursionando sobre as modificações teóricas processadas em diferentes conjunturas, o autor aponta o olhar sobre as macro-teorizações cedendo, ao longo do tempo, lugar ao tema dos significados sociais da materialidade baseados na lógica subjetiva dos múltiplos atores.

Em termos mais explicito, o momento da transição teórica é assim formulado:

O fulcro da teoria explicativa deixou de privilegiar o aumento das exclusões econômicas e sociais: o questionamento do por que os grupos se mobilizam deixou de se ater aos graus de carências ou marginalizações, sejam elas advindas do mundo do trabalho ou daquelas que marcam o cotidiano dos bairros populares. Parece ter havido um deslocamento analítico de certa importância, pois nessa ótica os atores sociais produzem tramas que estão referenciadas mas não atreladas às condições materiais objetivas. Em suma: não importa mais a magnitude da exploração, espoliação ou opressão, mas o significado que grupos categorias ou classes atribuem a esses processos (p. 105).

É com esse pressuposto que o autor acrescenta à noção de espoliação, modulada por determinantes macro-estruturais, o sentimento coletivo da percepção de um bem material ou cultural que está em falta. A busca de um caminho analítico mediador impóe a necessidade de estudar a vida em crise para além de um retrato empirista da pobreza, superando também a elaboração de explicações culturais sem raízes nas condiçôes objetivas.

Refletindo sobre a questão urbana do anos de 1990, reporta-se Kowarick ao país que não conse- guiu caminhar na direção de seu próprio progresso, fazendo surgir o cidadão de primeira e o de terceira classe, o morador de habitações subnormais submetido a uma situação de medo: de ficar doente, desempregado, ser acidentado, humilhado, extorquido, espancado, preso ou torturado.

\section{A vulnerabilidade como categoria sociológica}

A categoria sociológica designada por vulnerabilidade vai servir de referência ao livro Viver em risco, constituindo-se como chave de leitura para interpretar a condição de vida e trabalho de segmentos sociais destituídos de estabilidade, garantia, direitos e proteção social. Nessa obra, o tema da moradia é uma das questões mais discutidas, não se detendo apenas nas condiçôes precárias de alojamento, mas também nos processos de autoconstrução realizados em colaboração com a família, por meio de uma cota de trabalho não remunerado.

A autoconstrução é, portanto, o exemplo do sobre-trabalho com aparência de ganho pessoal, tendo em vista a importância que ela assume no universo das expectativas de segurança familiar. As moradias inacabadas e a dificuldade de concluir os projetos revelam, por outro lado, um déficit permanente que expressa a distância entre sonho e possibilidade, a característica de provisoriedade que atravessa a linha da pobreza em várias dimensões da vida.

As periferias, vistas nessa obra por meio de pesquisa mais etnográfica, são enfocadas não só como lugares de ausências ou carências, mas aglomerados dotados de sociabilidades intensas: ajuda entre vizinhos, conversas, contatos, solidariedades e conflitos. São interações típicas de relações primárias tecidas na adversidade, no confronto entre internos e externos, ou na busca de direitos sociais e políticos. Destaca-se, nas formas precárias de moradia, a relação que se estabelece nos cortiços com o centro da cidade, incidindo sobre a renda proveniente do trabalho ocasional e do pequeno comércio.

No contexto da moradia e do cotidiano partilhados destacam-se as lutas experimentadas no dia a dia dos contrastes, evidenciando o que o planejamento urbano baseado na construção de periferias 
não conseguiu eliminar, não obstante a tentativa de afastamento dos pobres para acena mais oculta da cidade. O cortiço, observado de forma detalhada no livro, constitui a expressão dos contrastes, a teimosia dos usos "indevidos" dos espaços.

A reflexão sobre a política desenvolvida pelo Estado no tocante à questão social tem como referência exemplos de intervenção realizados nos Estados Unidos, fundamentados na virada neo-liberal do welfare dependency. O reforço à idéia de culpabilização das vítimas, bastante difundido no senso comum e em pronunciamentos de experts, retiraria a responsabilidade do Estado sobre a gestão das desigualdades sociais, transferindo o problema da violência e do conflito para o cidadão comum.

O Brasil seria também signatário dessa percepção de transferência aos indivíduos do ônus da questão social, contribuindo para o aumento da vulnerabilidade em descompasso com a consolidação democrática. É nessa perspectiva que a linguagem do senso comum e a do poder público tornam-se objeto de crítica, considerando-se estarem as condiçôes da vida cotidiana relacionadas com o modelo de gestão capitalista do país, baseado na vigência de um Estado mínimo.

A presença das desigualdades, do exército de reserva e da super-exploração da força de trabalho vem, desde 1980, na obra de Kowarick, pondo em evidência um diferente modo de interrogar a questão social, não pautado na idéia de filantropia ou de culpabilização dos chamados "excluídos".

No âmbito dos argumentos sobre o equacionamento da questão social emerge o tema da vulnerabilidade e da supremacia da racionalidade econômica sobre os fatores de ordem social. Nessa perspectiva é recuperada a linguagem do pensamento crítico francês, que trata o tema da "exclusão" levando em conta a construção cultural e a política dos considerados "sobrantes" e "inúteis" do mundo, conforme a terminologia de Robert Castel. A “culpabilização dos excluídos" diz respeito, portanto, às formas de segregação dirigidas aqueles não enquadráveis nas políticas de manutenção da força de trabalho. As chaves teóricas de leitura permitem assim relativizar discursos e superar os atenuantes da desigualdade, nem sempre evidentes ao primeiro olhar.
Os supostos genéricos também se curvam à evidência dos fatos. $\mathrm{O}$ autor reconhece que a situação de moradia melhorou para os pobres, na medida em que um substancial número de pessoas se encontra em situação mais segura e com melhor qualidade habitacional, fato que vem viabilizando o enfrentamento de momentos de crise. Pontua, entretanto, que

[...] essas afirmações devem ser entendidas enquanto indicação de um processo complexo e diverso, pois não se pode esquecer as $600 \mathrm{mil}$ pessoas que habitam cortiços, o aumento do número de favelados que atinge 1,1 milhão de indivíduos, o recente aparecimento de $10 \mathrm{mil}$ moradores de rua ou mesmo a situação precária de muitas residências (p. 218).

A vulnerabilidade do Brasil urbano circunscrevese também ao âmbito dos direitos escassos e da fragilidade de um Estado que não conseguiu realizar o monopólio da violência legítima, mantendo índices singulares de acumulação e superexploração da força de trabalho. Em termos concretos, a vulnerabilidade afirma-se por meio das modalidades do "viver em risco", isto é, habitar em cortiços e favelas, assim como transitar em ambientes inseguros e marcados por "ausência de políticas" do Estado. A vulnerabilidade se exprime, enfim, na condição de pobreza e conseqüente precariedade de acessos aos bens coletivos de consumo, acrescidas da falta de garantias sociais ou dificuldade de exercício dos direitos humanos.

$\mathrm{Na}$ reflexão sobre a moradia Lúcio Kowarick chama atenção para os significados do morar na favela, no cortiço, ou em habitação proveniente de autoconstrução. As especificidades dessas condições de residência estão reveladas em depoimentos, com significados permeados de estigmas. As vantagens do morar próximo ao centro, alegadas fundamentalmente por moradores de cortiços, associam-se ao desejo preponderante de ter garantias para contrabalançar a instabilidade do desemprego.

A riqueza dos depoimentos aparece na forma especial do uso da etnografia. As falas ilustram as vicissitudes do morador urbano às voltas com a tentativa de superar a condição do "viver em risco". As informações são conduzidas por articulação com o 
modelo teórico capaz de "traduzir" os depoimentos em expressão viva da condição de espoliação e vulnerabilidade. São falas que, para além de mera ilustração, iluminam a teoria, dando-lhe consistência e vida. Termos como "humilhação" ou "experiências de desrespeito" indicam modos a partir dos quais os moradores interpretam as situaçôes de hierarquia social e conflito de classes.

É possível pensar a vulnerabilidade urbana como parte de um processo que atinge as condiçōes do capitalismo brasileiro, não estando restritas a São Paulo, embora este, pela própria concentração da industrialização, com efeitos sobre as migraçōes e o déficit de integração social e econômica, aponte modos mais visíveis e radicais de enfrentamento da questão social.

É importante lembrar que São Paulo em períodos anteriores foi considerado o eldorado da possibilidade de ascensão social, havendo absorvido parte significativa de trabalhadores provenientes do Nordeste. Os sonhos do trabalho estável, da casa própria, da dignidade e do reconhecimento perpassaram representaçôes de segmentos significativos das classes populares. Nesse sentido, não é de estranhar que seja esta a cidade que reflete uma espécie de tipo ideal weberiano expressivo de uma modernidade paradoxal e inconclusa.

Se o crescimento das cidades nordestinas aponta padrōes semelhantes de segregação aos de São Paulo, é relevante mencionar, por outro lado, a existência de redes de apoio domésticos, seja por meio do trabalho em casas de classe média, seja pelas formas de solidariedade ainda vigentes em bairros periféricos, que permitem um patamar de reprodução das classes populares dentro de um mínimo necessário.

Programas de apoio provenientes do governo federal têm servido também de reserva temporária de manutenção de um padrão mínimo de sobrevivência. Há, portanto, à guisa de uma rápida comparação entre São Paulo e outras cidades brasileiras, padrōes semelhantes de déficit de moradia e atendimento de serviços coletivos, que se fazem acompanhar de programas governamentais compensatórios, incidindo sobre outras formas de precariedade. Nessa configuração, presença de desempregados ou ausentes do emprego formal reforçam o comércio ambulante e a oferta de serviços capazes de conferir novas formas de vulnerabilidade a serem aprofundadas no exame de outras cidades.

Da perspectiva política seria interessante examinar os efeitos de programas governamentais nas percepçóes de moradores e nas formas de construção de experiências associativas. Em cidades onde a presença de sindicatos é reduzida, o peso de associações articuladas a políticas governamentais é muito forte. Essas são situaçōes a serem observadas à luz de outras investigaçōes de natureza comparativa.

Por fim, gostaria de refletir sobre a riqueza crítica ou o capital intelectual proveniente das obras analisadas. A primeira das contribuiçōes, já acentuada ao longo do texto, refere-se à robustez teórica da interpretação sobre as cidades como totalidade de processos, estruturas e experiências sociais. Sem desprezar o plano micro-social no qual os dramas cotidianos tecem a tela das desigualdades, Lúcio Kowarick persegue os nexos mais amplos que dão sentido às formas desiguais de apropriação e distribuição do espaço urbano. "O dedo permanente na ferida" conduz o autor à difusão incessante da condição do morador da metrópole contemporânea, que trava uma verdadeira guerra de lugares para fixar-se em um mundo que lhe é hostil.

As marcas de classe são bastante fortes no pensamento do autor. Elas permitem criticar a culpabilização dos "excluídos" nos discursos que bebem nas matrizes do pensamento liberal, em suas vertentes mais contemporâneas, com repercussōes sobre a formulação de políticas públicas.

A permanência ou a recorrência de idéias na produção intelectual de Lúcio Kowarick levam a supor uma cronologia de temas baseada nas seguintes ênfases: 1970 - expansão urbana e espoliação; 1980 - movimentos e conflitos urbanos; a partir de 1990, cidadania, direitos e violência. Observa-se, no entanto, que esses conceitos estão articulados e revisitados no conjunto da obra. Algumas renovações também se destacam. A reflexão sobre a espoliação torna-se mais complexa, agregando os conceitos de desfiliação e desenraizamento, ambos baseados nos efeitos das práticas de internacionalização da economia sobre a ordem cultural e política. 
A análise de políticas estatais voltadas para a correção de desníveis sociais permite uma comparação entre modelos vigentes em outros países, ampliando o escopo das teorizaçôes iniciais circunscritas ao contexto do capitalismo periférico emergente. $\mathrm{O}$ tema da cidadania é também revisitado, tendo em vista a fragilidade de políticas sociais e a característica predatória do capitalismo brasileiro, não amenizadas com os dividendos produzidos por movimentos sociais. Estes, com atuação atualmente mais restrita, não conseguiram aumentar a área de influência no âmbito das políticas públicas e ampliar espaços nas esferas mais decisórias do poder.

Outras temáticas são acrescidas à pesquisa sobre a vida urbana. O olhar sobre a violência constitui uma espécie de nova variável analítica que se agrega à condição do viver citadino. Não sendo prerrogativa de uma classe social, a problemática da violência atinge setores significativos da sociedade, inserindo-se, porém, de forma peculiar em habitaçôes marcadas por condições precárias. São lugares que abrigam traficantes e redes de comércio ilegal de drogas, tornando os moradores cúmplices de cenas atravessadas pelo medo da denúncia e incapacidade de reação.

É no mergulho por dentro dos bairros periféricos que a pesquisa desenvolvida com apoio de estudantes da USP descobre hierarquias de poder e estratégias de silêncio, configuradas como uma espécie de "mundo à parte". É nesse espaço que se apresenta uma "miséria do mundo", para usar o título do livro de Bourdieu (1997), mencionado e elogiado pelo autor, em uma das passagens de Viver em risco. Também aí se desenvolve o circuito $\mathrm{da}$ violência que atinge os desempregados e os sem perspectiva de inserção no mundo do trabalho, que percebem na droga o caminho fácil de sobrevivência e ascensão social.

A reflexão sobre a moradia como expressão da vulnerabilidade social constitui um dos elementos centrais e recorrentes da obra do autor, apresentando-se como sintoma da espoliação e das lutas pela dignidade e sobrevivência na cidade. O olhar voltado para as condições de reprodução acentua a moradia como fato social que alude às experiências aviltantes e aos modos de atravessar diferentes fron- teiras: A da legalidade e ilegalidade, a da extensão do sobre-trabalho por meio da autoconstrução, a da violência como elo estruturante da vida social.

Se no âmbito do trabalho as formas coletivas de resistência têm registros mais evidentes nos sindicatos, o espaço da moradia caracteriza-se por apontar formas difusas de organização, ora lideradas por associações, ora amparadas por instituições religiosas, programas governamentais e práticas associados a Ongs. É, portanto, na moradia que se destaca a situação de precariedade de amplos segmentos populares, fazendo emergir sentimentos sociais de desproteção e aviltamento. Trata-se de uma condição que se expressa fortemente no depoimento de moradores de favelas, cortiços e residências precárias situadas em bairros da periferia da cidade. A situação de moradia exprime também a condição de nomadismo a que está sujeita parte significativa da população.

Perpassa também nas pesquisas de Lúcio Kowarick a incorporação das contradiçốes urbanas ou da espoliação traduzidas em sentimentos. A honra aviltada pela promiscuidade do ambiente, a latrina partilhada sem privacidade, o medo de sair às ruas, o silêncio da violência doméstica estampada no corpo. Trata-se de uma espoliação que não é só física, mas psicológica, explicitada em comoventes depoimentos concedidos por moradores. Nessa direção, personagens de Vila Guiomar e do bairro Três Marias expõem os reveses da moradia e os sacrifícios da autoconstrução que permeiam suas vidas, na alternância entre o sonho e a chamada realidade. As falas dos moradores apresentadas em depoimentos tecem a atualidade da espoliação urbana vigente na persistência da desigualdade e das contradições urbanas.

O risco apontado na teoria dos macroprocessos estruturais valida-se em argumentos explicitados no medo, nas dificuldades da vida e na labuta permanente. Processos que contribuem, nesse sentido, para que o Estado se exima de seu papel de agente de políticas de intervenção e gestão do espaço público. O risco não é, entretanto, uma condição de casualidade, mas uma categoria social por meio da qual é possível ler a vida de moradores urbanos pertencentes não só aos segmentos mais desprovidos de bens econômicos e sociais. 
A busca da especificidade brasileira, incluindo também as características da Nuestra América, está presentes nas preocupações de Lúcio Kowarick com a generalidade das teorias. Nosso pós-modernismo, afirma o autor, "não é o policlassismo da ecologia verde. Está mais para o cinzento esverdeado, mistura de pobreza violência e desemprego" (Escritos urbanos, p. 120). A problemática urbana englobaria, assim, vasta e variada gama de teorias com longa intercessão com dinâmicas essenciais à sociedade.

Por fim, algumas observaçôes sobre as imagens presentes nos livros analisados, considerando-se que elas complementam o texto, auxiliam a tarefa das ciências sociais de tornar visível o oculto. $\mathrm{O}$ livro Escritos urbanos é ilustrado pelo fotógrafo Tomás Rezende, contendo registros do abandono, do trabalho estafante, do cansaço em transportes coletivos vivenciados por homens mulheres e crianças. Traz também imagens de mobilizações urbanas, apontando a cidade em seu cotidiano múltiplo e descontínuo.

O livro Viver em risco é também permeado por fotografias. Do ponto de vista estético, os registros em cinza, preto e branco são a metáfora daquela realidade mais crua e distante do observador comum. Concordo com Vera Telles quando no prefácio a essa obra afirma que os registros fotográficos de Antonio Saggese ultrapassam o sentido restrito da ilustração. São, portanto, espécies de imagens-narrativas, aquelas que "valem mais que mil palavras", pois produzem emoçôes, revelam as marcas de desigualdade em espaços escuros metaforizados em recantos nos quais o olhar da modernidade, quando ousa penetrar, o faz de modo sutil, sombreado e quase obscuro. $\mathrm{O}$ sujo das paredes descascadas, o desalinho das peças, as roupas jogadas quando não penduradas, em fios descontínuos, estão bem distantes da poesia de Noel Rosa em "chão de estrelas", expressando visualmente o viver em risco ou a experiência cotidiana da vulnerabilidade citadina.

Se questão urbana necessita de uma dose de utopia e desejo, como pensa Lúcio Kowarick, sua investigação certamente contribui para desvendar caminhos, sendo uma espécie de lupa para pensar as cidades em sua complexidade trágica e criativa.
Nota

1 Sobre o movimento dos quebra-quebras em São Paulo, ver, por exemplo, Barreira e Stroh, (1983).

\section{BIBLIOGRAFIA}

ARENDT, Hannah. (1991), A condição humana. Rio de Janeiro, Forense Universitária.

BARREIRA Irlys A. F. \& STROH, Paula. (1983), “O movimento dos desempregados nas ruas: uma prática fora de tempo e lugar?”. Espaço e Debates, ano III.

BOURDIEU, Pierre (coord.). (1997), A miséria do mundo. Rio de Janeiro, Vozes.

CARDOSO, Ruth. (1983), "Movimentos sociais urbanos: balanço crítico", in Bernardo Sorj e Maria Hermínia Tavares de Almeida (orgs.), Sociedade e Política no Brasil pós-64, São Paulo, Brasiliense.

CASTELLS, Manuel. (1980), Cidade, democracia e socialismo. Rio de Janeiro, Paz e Terra. . (1983), A questão urbana. Rio de Janeiro, Paz e Terra.

KOWARICK, Lúcio. (1983), A espoliação urbana. São Paulo, Paz e Terra.

. (1984), "Os caminhos do encontro, as lutas sociais em São Paulo na década de 70”. Cultura e Politica, 2.

KOWARICK, Lúcio \& BRANT, Vinicius Caldeira (orgs.). (1976), São Paulo 1975: crescimento e pobreza. São Paulo, Loyola.

OLIVEIRA, Francisco de. (1994), "Estado, sociedade, movimentos e políticas públicas no limiar do século XXI”. Rio de Janeiro, Programa de investigação e comunicação.

TELLES, Vera da Silva. (1982), "O bairro e a fábrica: a luta dos metalúrgicos em São Paulo". Cedec, mimeo.

THOMPSON, P. (1979), Tradicion, revuelta y consciencia de clase. Barcelona, Editorial Crítica. 